\title{
Need for medication to complement catecholamines in smoking cessation of hardcore smokers
}

\author{
This article was published in the following Dove Press journal: \\ Neuropsychiatric Disease and Treatment \\ 18 September 2017 \\ Number of times this article has been viewed
}

\author{
Atsuko Kawai ${ }^{1,2}$ \\ Masatake Kurita ${ }^{1,3,4}$ \\ Satoshi Nishino $0^{3,4}$ \\ Eishin Hirata ${ }^{5}$ \\ Tadahiro Sato ${ }^{5}$ \\ Yoshiro Okubo' \\ 'Department of Psychiatry and \\ Behavioral Science, Nippon Medical \\ School, Bunkyo-ku, ${ }^{2}$ Total Health \\ Clinic, Nanyo, ${ }^{3}$ Natori Station \\ Front Clinic, Natori, ${ }^{4}$ Laboratory \\ of Pharmacotherapy of Life-Style \\ Related Diseases, Graduate School \\ of Pharmaceutical Sciences, Tohoku \\ University, Sendai, Miyagi, ${ }^{5}$ Sato \\ Hospital, Nanyo, Japan
}

\begin{abstract}
Many smokers find it difficult to stop smoking without assistance. The antidepressants bupropion and nortriptyline can aid smoking cessation. The main aim of this study was to understand the pathophysiology of smoking cessation better based on biological backgrounds. We investigated the following biological markers for any alterations during smoking cessation in the absence of pharmacotherapy: the dopamine metabolite homovanillic acid (HVA), the noradrenaline metabolite 3-methoxy-4-hydroxyphenylglycol (MHPG) and brain-derived neurotrophic factor (BDNF). Assessment and blood sampling were performed at a baseline (the start) time point and at a critical time point during smoking cessation. Seven of 30 smokers quit during a 16-week follow-up period; these smokers were defined as remission group from tobacco dependence. The remaining 23 smokers were categorized as hardcore smokers. The smoking group was compared with 23 non-smokers matched for age and gender. We compared blood levels of biological markers in each of the three groups. The hardcore smoker group showed significant decreases in HVA and MHPG levels between baseline and the critical time point ( $p=0.018$ and $p=0.033$, respectively). However, the remission from tobacco dependence group exhibited no significant changes in any of the biomarkers examined. They had lower scores on the Minnesota nicotine withdrawal scale than the hardcore smoker group $(p=0.002)$. The hardcore smoker group had higher MHPG and BDNF levels than the non-smoker group ( $p=0.002$ and $p<0.001$, respectively). Hardcore smokers experience severe nicotine withdrawal symptoms. Nicotine withdrawal is associated with catecholamine deficiency. The resulting withdrawal symptoms make quitting difficult for hardcore smokers. These hardcore smokers may require medication to compensate for the catecholamine deficit. Non-nicotinic medications such as bupropion, nortriptyline, or varenicline may be required to bolster the catecholamine deficit in hardcore smokers.
\end{abstract}

Keywords: brain-derived neurotrophic factor, dopamine, nicotine, noradrenaline, tobacco, withdrawal symptoms

\section{Introduction}

Smoking is reported to be the single largest cause of premature death in developed countries. ${ }^{1}$ Smoking-related illnesses constitute a major public health problem in contemporary society, with smoking contributing to the prevalence of several chronic diseases. ${ }^{2}$ In the United States and Europe, $70 \%$ of all smokers have considered quitting at least once. ${ }^{3}$ Nicotine-related disorders are some of the psychiatric disorders defined by the Diagnostic and Statistical Manual for Mental Disorders, 5th Edition (DSM-5). ${ }^{4}$ Randomized trials using objective measures of abstinence reported 6-month cessation rates of $8 \%$ for nicotine, $18 \%$ for alcohol, $47 \%$ for cocaine, and $44 \%$ for opioids. ${ }^{5}$ Thus, evidence from placebo cessation rates indicates that nicotine may be more difficult to give up than alcohol, cocaine, and opioids.
Correspondence: Masatake Kurita Natori Station Front Clinic, 428-I Hachiman Tegurada, Natori, Miyagi $98 \mathrm{I}-\mathrm{I} 23 \mathrm{I}$, Japan

$\mathrm{Tel}+8 \mathrm{I} 223825955$

Fax +8I 223826505

Email kurita@nisiguti-cl.jp (c) (1) (-) 2017 Kawai et al. This work is published and licensed by Dove Medical Press Limited. The full terms of this license are available at https://www.dovepress.com/terms.php (c) $\mathrm{BY}$ and incorporate the Creative Commons Attribution - Non Commercial (unported, v3.0) License (http://creativecommons.org/licenses/by-nc/3.0/). By accessing the work you hereby accept the Terms. Non-commercial uses of the work are permitted without any further permission from Dove Medical Press Limited, provided the work is properly attributed. For permission for commercial use of this work, please see paragraphs 4.2 and 5 of our Terms (https://www.dovepress.com/terms.php). 
Smoking delivers nicotine rapidly to the central nervous system, where the molecule facilitates release of several neurotransmitters. ${ }^{6}$ The rationale behind the use of nicotine replacement therapies is intuitive. However, it remains unclear why non-nicotine pharmacotherapies are effective. Three non-nicotine pharmacotherapies currently prescribed for smoking cessation are bupropion, nortriptyline, and varenicline..$^{7-9}$ Bupropion is presumed to facilitate cessation via its ability to inhibit neuronal reuptake of dopamine and noradrenaline, both of which are involved in nicotine dependence and withdrawal. ${ }^{8}$ Nortriptyline is a tricyclic antidepressant that inhibits reuptake of noradrenaline. ${ }^{10}$ The proposed mechanism of action of varenicline is modulation of dopamine release in reward areas. ${ }^{11}$ Dopaminergic mechanisms have been implicated in both the reward aspects of nicotine and in the manifestations of nicotine withdrawal syndrome. ${ }^{12,13}$

Cell bodies of the midbrain dopamine system are largely located in the ventral tegmental area (VTA) A10 brain nuclei. They project axons to the caudate putamen, nucleus accumbens, and prefrontal cortex. ${ }^{14}$ Nicotine withdrawal symptoms may be mediated through a noradrenergic mechanism. ${ }^{15}$ Furthermore, brain-derived neurotrophic factor (BDNF) influences the levels of monoamines, which may be closely related to addiction. ${ }^{16}$ In fact, BDNF levels in the striatum and nucleus accumbens are increased by nicotine. ${ }^{17}$ Although these findings suggest that nicotine dependence or withdrawal may be associated with catecholamines and BDNF levels, their role during smoking cessation remains unclear.

The objective of this study was to understand the pathophysiology of smoking cessation better in a biological context. To do this, we measured biological marker levels (catecholamines and BDNF) at a time point prior to smoking cessation and at a critical time point during abstinence. We then compared biological marker levels in hardcore smokers, remission from tobacco dependence smokers and non-smokers.

\section{Methods}

\section{Subjects}

Study smokers $(n=30)$ were recruited from a total of 33 subjects admitted to the outpatient facility of Total Health Clinic, Koutokukai (Yamagata, Japan). All smokers met the Diagnostic and Statistical Manual for Mental Disorders, 4th Edition-Text Revision (DSM-IV-TR) ${ }^{18}$ criteria for nicotine-related disorders. The diagnosis of nicotine dependence was evaluated using the tobacco dependence screener scale (TDS). Subjects were defined as nicotine-dependent if they had a TDS score of $\geq 5$ at the baseline screening appointment. ${ }^{19}$ Seven smokers maintained abstinence up to 16 weeks. These 7 smokers met the criteria of early full remission from tobacco dependence according to the DSMIV-TR. ${ }^{18}$ The remaining 23 subjects were defined as hardcore smokers. A flowchart describing subject selection is shown in Figure 1. The control group consisted of non-smokers matched to the hardcore smoker group for gender and age.

In previous reports, withdrawal symptoms peaked within the first week ${ }^{20}$ and most relapses occurred in the first 8 days. ${ }^{21}$ Consequently, abstinence after 1 week or the time point immediately prior to smoking again was defined as the critical time point.

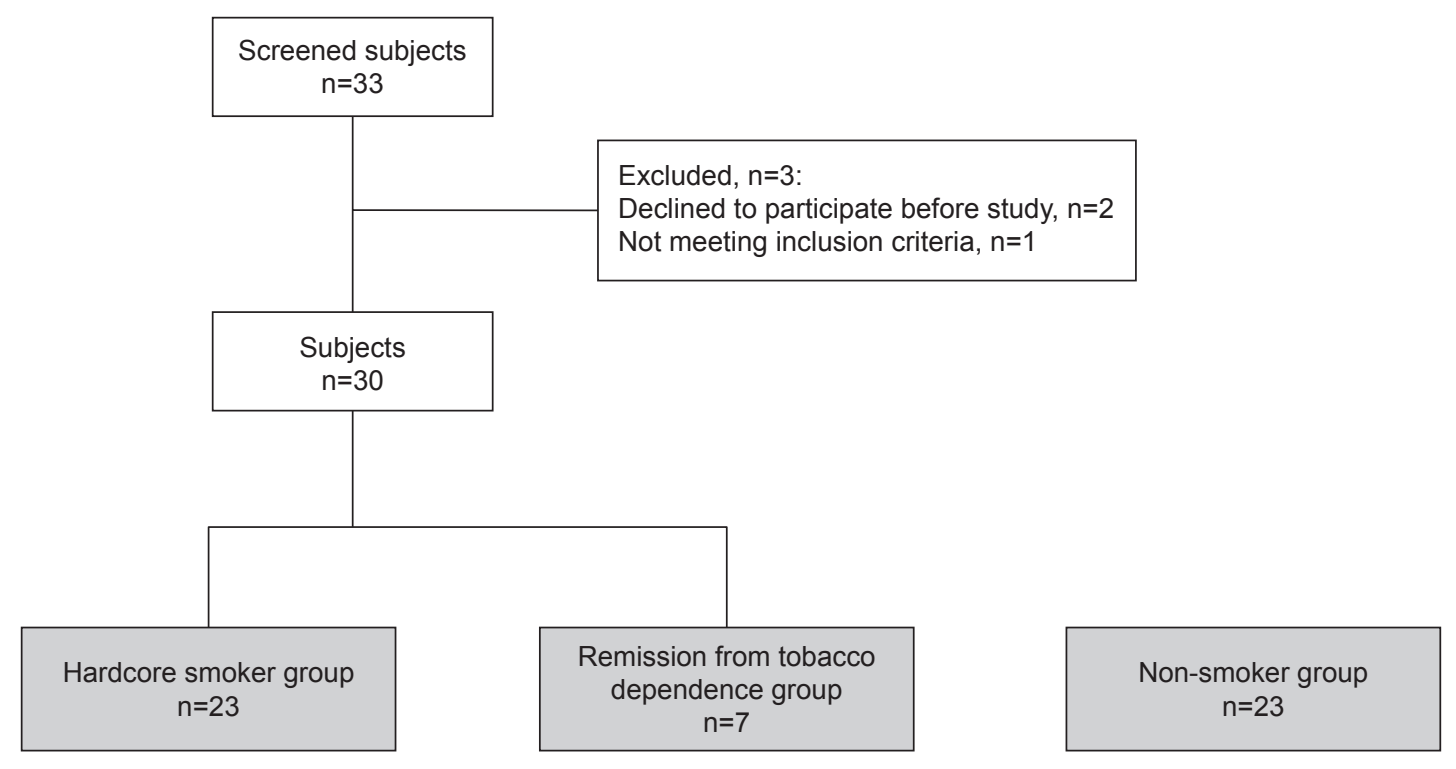

Figure I Flowchart of the subject numbers throughout the study. 
Eligibility was evaluated by structured interview, physical examination, and laboratory tests. None of the subjects had any history or evidence of a serious medical or neurological illness, psychiatric disorder, substance abuse, or dependence on any substance other than nicotine. None of the subjects had received any psychotropic drug or hormone therapies, including oral contraceptives. Control subjects were recruited by advertising via a notice board in the same local population. Control subjects who had never smoked in their lifetime were admitted to the study as non-smokers.

Written informed consent was obtained from all participants after the procedures were fully explained. The study protocols were approved by the Ethics Committee of Sato Hospital and the Ethics Committee of Graduate School of Pharmaceutical Science, Tohoku University. This study was performed according to the ethical standards of the Declaration of Helsinki.

\section{Assessments}

Nicotine dependence was assessed using the Fagerström test for nicotine dependence (FTND). ${ }^{22}$ Nicotine withdrawal symptoms were assessed using the Minnesota nicotine withdrawal scale (MNWS). ${ }^{23}$ To check for abstinence, expiratory carbon monoxide (CO) levels were measured using a Micro III Smokerlyzer ${ }^{\circledR}$ (Bedfont Scientific Ltd., Bedfont, UK). Confirmation of abstinence was defined as an expiratory CO level below 8 ppm.

\section{Sample collection}

Blood was obtained by venipuncture in blood-collection tubes containing the anticoagulant ethylenediamine tetraacetic acid. The tubes were immediately cooled to $4^{\circ} \mathrm{C}$ and centrifuged at $2,000 \times g$ for $20 \mathrm{~min}$. The resulting plasma samples were kept at $-80^{\circ} \mathrm{C}$ until analysis.

\section{Assays}

The plasma levels of homovanillic acid (HVA) and 3-methoxy-4-hydroxyphenylglycol (MHPG) were analyzed by high-performance liquid chromatography with electrochemical detection, ${ }^{24-26}$ to evaluate levels of dopamine and noradrenaline in the brain, respectively. Plasma levels of BDNF were measured using a sandwich ELISA kit, BDNF Emax $^{\circledR}$ Immunoassay System (Promega Corporation, Fitchburg, WI, USA) as described previously. ${ }^{27}$

\section{Data analysis}

Evaluation of normal distribution of data was performed using the Shapiro-Wilk test. Comparisons between the hardcore smokers and the remission from tobacco dependence groups were performed using the Mann-Whitney $U$ test (nonparametric unpaired test). Comparisons between the three individual groups were performed using analysis of variance (ANOVA), and Scheffe's $F$ test was used as a post hoc test. Comparisons between the baseline and critical time point were performed using the Wilcoxon signed-rank test (nonparametric paired test). Categorical comparisons were conducted using the $\chi^{2}$ test. Data are presented as means \pm standard deviation. Values of $p<0.05$ were considered statistically significant. All analyses were carried out using SPSS 16.0J for Mac (SPSS Inc., Chicago, IL, USA).

\section{Results}

\section{Characteristics of the subjects}

A total of 33 smokers were screened. One subject failed to meet the inclusion criteria because of a diagnosis of a major depressive disorder. Two subjects declined to participate prior to study initiation. The first analysis therefore included 30 subjects (Figure 1). Seven of the 30 smokers (23.3\%) achieved smoking cessation without pharmacotherapy during the 16 weeks of follow-up; therefore, these smokers were defined as remission from tobacco dependence ( 6 men, 1 woman; mean age: $47.0 \pm 15.6$ years). The remaining 23 smokers were defined as hardcore smokers (14 men, 9 women; mean age $39.3 \pm 12.5$ years) (Figure 1). The mean smoking cessation period was $7.1 \pm 6.5$ days. The 23 non-smokers recruited for this study were matched with the members of the hardcore smoking group for age and gender (14 men, 9 women; mean age $40.5 \pm 14.3$ years). The characteristics of the subjects are summarized in Table 1. No significant differences were found between the hardcore smoker, remission from tobacco dependence, and non-smoker groups in terms of gender, age, or CO levels at baseline (Table 1).

\section{Comparisons of the hardcore, remission from tobacco dependence, and non- smoker groups at baseline assessments}

There was no significant difference in the FTND score between the hardcore smoker group and the remission from tobacco dependence smoker group (6.9 \pm 1.6 points vs $6.1 \pm 1.6$ points; Mann-Whitney $U$ unpaired test, $p=0.190$ ) (Table 1). In contrast, the MNWS scores in the hardcore smoking group and the remission from tobacco dependence group at baseline were $10.6 \pm 6.8$ and $3.3 \pm 2.2$ points, respectively. The group of remission from tobacco dependence had significantly lower MNWS scores than the 
Table I Demographic and other baseline characteristics of the selected study population

\begin{tabular}{|c|c|c|c|c|c|c|c|c|}
\hline & \multirow{3}{*}{$\begin{array}{l}\text { Hardcore } \\
\text { smoking } \\
\text { group } \\
(n=23)\end{array}$} & \multirow{3}{*}{$\begin{array}{l}\text { Remission } \\
\text { from tobacco } \\
\text { dependence } \\
\text { group }(n=7)\end{array}$} & \multirow{3}{*}{$\begin{array}{l}\text { Non-smoking } \\
\text { group }(n=23)\end{array}$} & \multirow[t]{3}{*}{$\boldsymbol{F}$} & \multirow[t]{3}{*}{$p$-value } & \multicolumn{3}{|c|}{ ANOVA post hoc Scheffe } \\
\hline & & & & & & Hard-Remi & Hard-Non & Remi-Non \\
\hline & & & & & & $p$-value & $\overline{p \text {-value }}$ & $\overline{p \text {-value }}$ \\
\hline \multicolumn{9}{|l|}{ Gender, n (\%) } \\
\hline Male & $14(60.9)$ & $6(85.7)$ & $14(60.9)$ & & 0.475 & & & \\
\hline Female & $9(39.1)$ & $\mathrm{I}(\mathrm{I} 4.3)$ & $9(39.1)$ & & & & & \\
\hline Mean age (years) & $39.3(12.5)$ & $47.0(15.6)$ & $40.5(14.3)$ & 0.86 & 0.431 & 0.436 & 0.958 & 0.550 \\
\hline Age of first use (years) & $18.3(2.8)$ & $18.6(1.4)$ & & & 0.886 & & & \\
\hline Duration of use (years) & $20.0(10.0)$ & $29.3(15.1)$ & & & 0.096 & & & \\
\hline Amount of use (cigarettes/day) & $18.5(5.5)$ & $26.9(16.0)$ & & & 0.311 & & & \\
\hline Periods ${ }^{\#}$ (days) & $7.1(6.5)$ & $6.4(4.5)$ & & & 0.962 & & & \\
\hline CO level (ppm) & $13.0(7.4)$ & I4.3 (9.8) & & & 0.980 & & & \\
\hline \multicolumn{9}{|l|}{ Assessments } \\
\hline FTND (points) & $6.9(1.6)$ & $6.1(1.6)$ & & & 0.190 & & & \\
\hline MNWS (points) & $10.6(6.8)$ & $3.3(2.2)$ & & & $0.002 * *$ & & & \\
\hline \multicolumn{9}{|l|}{ Biomarkers } \\
\hline HVA (ng/mL) & $10.25(3.20)$ & $7.52(\mathrm{I} .6 \mathrm{I})$ & $8.83(3.23)$ & 2.08 & 0.135 & 0.224 & 0.297 & 0.795 \\
\hline MHPG (ng/mL) & $12.06(2.69)$ & II.II (2.90) & $9.21(2.00)$ & 7.95 & $0.001 * *$ & 0.994 & $0.002 * *$ & 0.056 \\
\hline BDNF (pg/mL) & $7,634(4,257)$ & $6,060(3,438)$ & $2,630(1,65 I)$ & 13.84 & $<0.001 * * *$ & 0.538 & $<0.00 I^{* * *}$ & 0.060 \\
\hline
\end{tabular}

Notes: The values represent the mean (SD). Statistically significant $(* * p<0.01$, *** $p<0.00 \mathrm{I})$. Statistical analyses were performed using $\chi^{2}$ test, Mann-Whitney $U$ test (nonparametric test), and ANOVA post hoc Scheffe. \#Periods between baseline and critical time point. Hard-Remi, hardcore smoker group versus remission from tobacco dependence group; Hard-Non, hardcore smoker group versus non-smoker group; Remi-Non, remission from tobacco dependence group versus non-smoker group.

Abbreviations: CO, carbon monoxide in exhalation; FTND, Fagerström test for nicotine dependence; MNWS, Minnesota nicotine withdrawal scale; HVA, homovanillic acid; MHPG, 3-methoxy-4-hydroxyphenylglycol; BDNF, brain-derived neurotrophic factor; ANOVA, analysis of variance.

hardcore smoker group (Mann-Whitney $U$ unpaired test, $p=0.002$ ) (Table 1).

\section{Biomarkers}

Plasma MHPG and BDNF levels in the hardcore smoker group $(12.1 \pm 2.7 \mathrm{ng} / \mathrm{mL}$ and $7,634 \pm 4,257 \mathrm{pg} / \mathrm{mL})$ were significantly higher than those of the non-smoker group $(9.2 \pm 2.0 \mathrm{ng} / \mathrm{mL}$ and $2,630 \pm 1,651 \mathrm{pg} / \mathrm{mL}$ ) (ANOVA post hoc Scheffe, $p=0.002$ and $p<0.001$, respectively) (Table 1). However, no significant differences were found between the hardcore smoker group $(10.3 \pm 3.2 \mathrm{ng} / \mathrm{mL})$ and the non-smoker group $(8.8 \pm 3.2 \mathrm{ng} / \mathrm{mL})$ in plasma HVA levels (ANOVA post hoc Scheffe, $p=0.297$ ) (Table 1). However, the BDNF levels of the remission from tobacco dependence group tended to be higher than those of the non-smoker group and were similar to those of hardcore smokers (ANOVA post hoc Scheffe, $p=0.060$ ). There were no significant differences among the hardcore smoker, remission form tobacco dependence and non-smoker groups in term of gender, age or CO levels at baseline.

\section{Variation between baseline and critical time point}

\section{Hardcore smoker group}

Plasma HVA levels decreased from baseline $(10.3 \pm 3.2 \mathrm{ng} / \mathrm{mL})$ to the critical time point $(8.3 \pm 2.1 \mathrm{ng} / \mathrm{mL})$ (Wilcoxon signedrank paired test, $p=0.018$ ) (Table 2). Plasma MHPG levels also decreased from baseline $(12.1 \pm 2.7 \mathrm{ng} / \mathrm{mL})$ to the critical time point $(11.2 \pm 2.5 \mathrm{ng} / \mathrm{mL}$ ) (Wilcoxon signed-rank paired test, $p=0.033$ ) (Table 2). Plasma BDNF levels did not change significantly between baseline $(7,634 \pm 4,257 \mathrm{pg} / \mathrm{mL})$ and the critical time point $(8,378 \pm 4,643 \mathrm{pg} / \mathrm{mL}$ ) (Wilcoxon signedrank paired test, $p=0.429$ ) (Table 2).

\section{Remission from tobacco dependence group}

The changes in the plasma HVA, MHPG, and BDNF levels from the baseline to the critical time point in the remission from tobacco dependence group were $7.5 \pm 1.6$ to $22.6 \pm$ $34.8 \mathrm{ng} / \mathrm{mL}, 11.1 \pm 2.9$ to $13.5 \pm 9.8 \mathrm{ng} / \mathrm{mL}$, and $7,634 \pm 4,257$ to $8,378 \pm 4,643 \mathrm{ng} / \mathrm{mL}$, respectively. The changes in the

Table 2 Changes of biomarkers between baseline and critical time point in each group

\begin{tabular}{lcll}
\hline & Baseline & $\begin{array}{l}\text { Critical } \\
\text { time point }\end{array}$ & p-value \\
\hline Hardcore smoker & group $(\mathbf{n}=\mathbf{2 3})$ & & \\
HVA $(\mathrm{ng} / \mathrm{mL})$ & $10.3(3.2)$ & $8.3(2.1)$ & $0.018^{*}$ \\
MHPG $(\mathrm{ng} / \mathrm{mL})$ & $12.1(2.7)$ & $11.2(2.5)$ & $0.033^{*}$ \\
BDNF $(\mathrm{pg} / \mathrm{mL})$ & $7,634(4,257)$ & $8,378(4,643)$ & 0.429 \\
Remission from tobacco dependence group $(\mathbf{n}=\mathbf{7})$ & \\
HVA $(\mathrm{ng} / \mathrm{mL})$ & $7.5(1.6)$ & $22.6(34.8)$ & 0.398 \\
MHPG $(\mathrm{ng} / \mathrm{mL})$ & $11.1(2.9)$ & $13.5(9.8)$ & 0.866 \\
BDNF $(\mathrm{pg} / \mathrm{mL})$ & $6,060(3,438)$ & $5,744(3,894)$ & 0.735 \\
\hline
\end{tabular}

Notes: The values represent the mean (SD). Statistical analyses were performed using Wilcoxon signed-rank test (paired test). Statistically significant $\left({ }^{*} p<0.05\right)$. Abbreviations: HVA, homovanillic acid; MHPG, 3-methoxy-4-hydroxyphenylglycol; BDNF, brain-derived neurotrophic factor. 
plasma levels of all biomarkers examined from the baseline to the critical time point in the remission from tobacco dependence group were not significant (Wilcoxon signedrank paired test, $p=0.398, p=0.866$, and $p=0.429$, for HVA, MHPG, and BDNF, respectively) (Table 2).

\section{Discussion}

The precise mechanisms by which non-nicotinic medications aid smoking cessation are not well understood, whereas nonnicotine pharmacotherapies have been proven to increase abstinence rates. ${ }^{7,8}$ To our knowledge, this is the first study that examines changes in the biomarker levels during periods of smoking abstinence in hardcore smokers.

We found that both HVA and MHPG levels decreased significantly in the hardcore smoker group during abstinence. This suggests that hardcore smokers may experience a catecholamine deficit during acute nicotine deficiency.

The hardcore smoker group had significantly higher plasma levels of MHPG and BDNF compared with the non-smoker group. High levels of MHPG can be caused by chronic exposure to nicotine. Nicotine induces a dosedependent increase in noradrenaline levels in the paraventricular nucleus of the hypothalamus. ${ }^{28}$ Our results suggest that nicotine may cause hardcore smokers to develop high noradrenaline levels in the brain. This is the hallmark feature of nicotine dependence: decreased noradrenaline will induce nicotine craving. Hardcore smokers may have a difficult time adjusting to acute changes in brain catecholamines. DiFranza and Wellman proposed a sensitization-homeostasis model; a model of addiction that predicts what happens to the brain after smoking cessation. ${ }^{29}$ Our results suggest that nicotinic acetylcholine receptors mediate sensitivity to nicotine stimulus in the hardcore smoker group. Hardcore smokers may experience withdrawal symptoms mediated by decreases in dopamine and noradrenaline. Bupropion ${ }^{8}$ and nortriptyline ${ }^{10}$ are presumed to inhibit neuronal reuptake of dopamine and/or noradrenaline. These antidepressants may increase abstinence rates by increasing catecholamine levels. Hardcore smokers may require medications to complement both dopamine and noradrenaline, as these smokers have difficulty achieving catecholamine homeostasis.

Chronic exposure to nicotine is associated with increased levels of BDNF in the hippocampus and cerebral cortex. ${ }^{30}$ In a clinical study, active smokers had higher serum BDNF levels than that of non-smokers. ${ }^{31}$ Nicotine may have the effect of increasing brain BDNF levels. Our study results are consistent with these findings. Thus, BDNF levels may be increased by smoking, regardless of nicotine dependence. However, BDNF levels did not change significantly between the baseline and the critical time point in this study. In animal studies, 21 days of exposure to psychotropic drugs were required to show increases in BDNF. ${ }^{32} \mathrm{Kim}$ et $\mathrm{al}^{33}$ reported that BDNF levels in smokers increased after a 2-month smoking cessation period. Thus, the interval between our baseline and critical time point may not be sufficiently long to evaluate the changes in BDNF.

Seven smokers in this study achieved abstinence without pharmacotherapy. This remission from tobacco dependence group had FTND scores similar to the hardcore smokers, suggesting similar levels of nicotine dependence $(p=0.190)$. However, the MNWS scores in the remission from tobacco dependence group were significantly lower than those of the hardcore smokers at baseline $(p=0.002)$. These findings suggest that MNWS scores may be a useful tool in distinguishing between people who may successfully quit smoking and hardcore smokers.

Many smokers find quitting difficult, whether they try on their own, or in response to social pressure. There may be a biological basis for this phenomenon, in which hardcore smokers suffer a biological vulnerability to nicotine withdrawal.

A limitation of our study is that the sample size of the group of remission from tobacco dependence is small. Therefore, significant differences in any biomarkers might not be discernible among the group of remission from tobacco dependence. Many smokers (excluding hardcore smokers) may have already quite smoking due to pressure for a non-smoking environment. Although it may be difficult to recruit subjects for remission from tobacco dependence, future studies will need to recruit more subjects to increase the statistical power of this research.

\section{Conclusion}

Nicotine withdrawal may result in deficiencies in both dopamine and noradrenaline in hardcore smokers. These findings suggest that hardcore smokers do not have sufficient catecholamine compensatory mechanisms, owing to acute nicotine depletion. For this reason, hardcore smokers may need medication to complement catecholamines, such as dopamine or noradrenaline.

\section{Acknowledgments}

We thank the study participants, without whom this study could not have been accomplished, as well as the following psychiatrists and staff of Total Health Clinic and Sato Hospital, Koutokukai: Yukio Numata, MD; Kuniko Watanabe, Kayoko Suga, Kazuo Kenmi, MD, PhD; Asao Hasegawa, MD; Masaaki Mitomo, MD; Yukihiro Takeuchi, 
$\mathrm{MD}, \mathrm{PhD}$; Hiroshi Yamamoto, MD; Maiko Kato, MD; and Kenji Takeyoshi, MD, PhD. This study was supported by funding from Koutokukai, Sato Hospital. The study did not receive funding from any pharmaceutical corporations.

\section{Disclosure}

The authors report no conflicts of interest in this work.

\section{References}

1. Peto R, Lopez AD, Boreham J, Thun M, Heath C Jr. Mortality from tobacco in developed countries: indirect estimation from national vital statistics. Lancet. 1992;339(8804):1268-1278.

2. Beaglehole R, Bonita R, Horton R, et al. Priority actions for the noncommunicable disease crisis. Lancet. 2011;377(9775):1438-1447.

3. Anderson JE, Jorenby DE, Scott WJ, Fiore MC. Treating tobacco use and dependence: an evidence-based clinical practice guideline for tobacco cessation. Chest. 2002;121(3):932-941.

4. American Psychiatric Association. Diagnostic and Statistical Manual of Mental Disorders. 5th ed. Arlington: American Psychiatric Association; 2013.

5. Moore RA, Aubin HJ. Do placebo response rates from cessation trials inform on strength of addictions? Int J Environ Res Public Health. 2012;9(1):192-211.

6. Calabresi P, Lacey MG, North RA. Nicotinic excitation of rat ventral tegmental neurones in vitro studied by intracellular recording. $\mathrm{Br} \mathrm{J}$ Pharmacol. 1989;98(1):135-140.

7. Richmond R, Zwar N. Review of bupropion for smoking cessation. Drug Alcohol Rev. 2003;22(2):203-220.

8. McRobbie H, Lee M, Juniper Z. Non-nicotine pharmacotherapies for smoking cessation. Respir Med. 2005;99(10):1203-1212.

9. Hughes JR, Stead LF, Lancaster T. Nortriptyline for smoking cessation: a review. Nicotine Tob Res. 2005;7(4):491-499.

10. Gillman PK. Tricyclic antidepressant pharmacology and therapeutic drug interactions updated. Br J Pharmacol. 2007;151(6):737-748.

11. Turner JR, Castellano LM, Blendy JA. Parallel anxiolytic-like effects and upregulation of neuronal nicotinic acetylcholine receptors following chronic nicotine and varenicline. Nicotine Tob Res. 2011;13(1): $41-46$.

12. Dani JA. Roles of dopamine signaling in nicotine addiction. $\mathrm{Mol}$ Psychiatry. 2003;8(3):255-256.

13. Kenny PJ, Markou A. Neurobiology of the nicotine withdrawal syndrome. Pharmacol Biochem Behav. 2001;70(4):531-549.

14. Bjorklund A, Dunnett SB. Fifty years of dopamine research. Trends Neurosci. 2007;30(5):185-187.

15. Itoh $\mathrm{H}$, Toyohira $\mathrm{Y}$, Ueno $\mathrm{S}$, et al. Upregulation of norepinephrine transporter function by prolonged exposure to nicotine in cultured bovine adrenal medullary cells. Naunyn Schmiedebergs Arch Pharmacol. 2010;382(3):235-243.

16. Hashimoto K, Shimizu E, Iyo M. Critical role of brain-derived neurotrophic factor in mood disorders. Brain Res Rev. 2004;45(2): 104-114.
17. Perna MK, Brown RW. Adolescent nicotine sensitization and effects of nicotine on accumbal dopamine release in a rodent model of increased dopamine D2 receptor sensitivity. Behav Brain Res. 2013;242: 102-109.

18. American Psychiatric Association. Diagnostic and Statistical Manual of Mental Disorders. 4th ed (DSM-IV-TR). Arlington, Virginia: American Psychiatric Association; 2000.

19. Kawakami N, Takatsuka N, Inaba S, Shimizu H. Development of a screening questionnaire for tobacco/nicotine dependence according to ICD-10, DSM-III-R, and DSM-IV. Addict Behav. 1999;24(2):155-166.

20. Hughes JR. Effects of abstinence from tobacco: valid symptoms and time course. Nicotine Tob Res. 2007;9(3):315-327.

21. Hughes JR, Keely J, Naud S. Shape of the relapse curve and long-term abstinence among untreated smokers. Addiction. 2004;99(1):29-38.

22. Heatherton TF, Kozlowski LT, Frecker RC, Fagerstrom KO. The Fagerstrom test for nicotine dependence: a revision of the Fagerstrom tolerance questionnaire. Br J Addict. 1991;86(9):1119-1127.

23. Hatsukami DK, Hughes JR, Pickens RW, Svikis D. Tobacco withdrawal symptoms: an experimental analysis. Psychopharmacology. 1984; 84(2):231-236

24. Kurita M, Nishino S, Numata Y, Okubo Y, Sato T. The noradrenaline metabolite MHPG is a candidate biomarker from the manic to the remission state in bipolar disorder I: a clinical naturalistic study. PLoS One. 2014;9(6):e100634.

25. Yeung PK, Buckley SJ, Pedder SC, Dingemanse J. Determination of 3,4-dihydroxyphenylacetic acid and 5-hydroxyindoleacetic acid in human plasma by a simple and rapid high-performance liquid chromatography assay. J Pharm Sci. 1996;85(4):451-453.

26. Yoshimura R, Nakamura J, Shinkai K, et al. An open study of risperidone liquid in the acute phase of schizophrenia. Hum Psychopharmacol. 2005;20(4):243-248.

27. Kurita M, Nishino S, Kato M, Numata Y, Sato T. Plasma brain-derived neurotrophic factor levels predict the clinical outcome of depression treatment in a naturalistic study. PLoS One. 2012;7(6):e39212.

28. Fu Y, Matta SG, Valentine JD, Sharp BM. Adrenocorticotropin response and nicotine-induced norepinephrine secretion in the rat paraventricular nucleus are mediated through brainstem receptors. Endocrinology. 1997;138(5):1935-1943.

29. DiFranza JR, Wellman RJ. A sensitization-homeostasis model of nicotine craving, withdrawal, and tolerance: integrating the clinical and basic science literature. Nicotine Tob Res. 2005;7(1):9-26.

30. Czubak A, Nowakowska E, Kus K, et al. Influences of chronic venlafaxine, olanzapine and nicotine on the hippocampal and cortical concentrations of brain-derived neurotrophic factor (BDNF). Pharmacol Rep. 2009;61(6):1017-1023.

31. Jamal M, Van der Does W, Elzinga BM, Molendijk ML, Penninx BW. Association between smoking, nicotine dependence, and BDNF Val66Met polymorphism with BDNF concentrations in serum. Nicotine Tob Res. 2015;17(3):323-329.

32. Nibuya M, Morinobu S, Duman RS. Regulation of BDNF and trkB mRNA in rat brain by chronic electroconvulsive seizure and antidepressant drug treatments. J Neurosci. 1995;15(11):7539-7547.

33. Kim TS, Kim DJ, Lee H, Kim YK. Increased plasma brain-derived neurotrophic factor levels in chronic smokers following unaided smoking cessation. Neurosci Lett. 2007;423(1):53-57.
Neuropsychiatric Disease and Treatment

\section{Publish your work in this journal}

Neuropsychiatric Disease and Treatment is an international, peerreviewed journal of clinical therapeutics and pharmacology focusing on concise rapid reporting of clinical or pre-clinical studies on a range of neuropsychiatric and neurological disorders. This journal is indexed on PubMed Central, the 'PsycINFO' database and CAS,

\section{Dovepress}

and is the official journal of The International Neuropsychiatric Association (INA). The manuscript management system is completely online and includes a very quick and fair peer-review system, which is all easy to use. Visit http://www.dovepress.com/testimonials.php to read real quotes from published authors. 